With such authorities as Baudelocque, Voigtel, Desormeaux, Velpeau, and especially Madame Boivin and Dr. Montgomery, I believe uterine hydatids to be always the result of sexual intercourse. The argument from analogy against this view has been clearly answered by Dr. Mnntgomery, and is perhaps needless to detail to persons familiar with the subject of this paper.

S. A - residing in Sydney-street, aged forty-two, of bilions temperament, but of active habits, and healthy, states as follows:- She is always regular as to the catamenia, except during utero-gestation and suckling; has had six children, now living; has but once suffered abortion, and that twelve years ago. After weaning her last child, which she suckled till eighteen months old, the menses immediately reappeared, and continued regular for three months - the usual period of her former conceptions after weaning : they now ceased.

At the expiration of three months from their cessation, there succeeded a daily stillicidium of blood, generally, but not invariably, black; being, at length, in gushes of ordinary hæmorrhage after every slight exertion, and these constantly attended with foreing pains like those of parturition.

The concomitant symptoms were now constant nausea, vomiting after the most simple food-gruel, tea, \&c., and, in consequence, great emaciation, pain at scrobiculus cordis, and in the bowels. As to her appearance, the breasts and abdomen were enlarged, but, she thought, not proportionately to their development at the same stage of her former pregnancies. The bulk of abdomen "seemed to lie very high up." The usual umbilical prominence had also lately occurred. This brings us nearly to the end of six months, the three last of which she designated a continned labour and flooding, and in the three last weeks of which only she had sought medical advice at the disperisary, at the end of which time she was thought so much better by the medical officer as to be dismissed cured.

This temporary respite was, however, in a few hours, succeeded by still more violent and regular labour pains, and severe flooding, under which circumstances she first applied to me for advice.

At the expiration of about twelve hours of yegular pains and hæmorrhage, about a wash-hand basonful of hydatids were discharged, adhering like an immense cluster of grapes to a bloody, spongy substance, resembling a degenerated pla. centa, which being macerated and cut into exhibited an aggregate of hydatids embedded in its substance. I could detect no investing membrane nor portion of a fotus.

The pains and hremorrhage now subsided, but in a few hours returned, when an almost equal quantity of hydatids were discharged, which last mass, unhappily, I had not an opportunity of examining, it having been inconsiderately removed ly the attendants, who supposed that having reserved the first I would not require to examine further. A discharge, quite unlistinguishable from lochia, followed, but no secretion of milk.

So far as the case detailed is concerned, I think, by reviewing it carefully, little doubt can be entertained as to how the hydatid disease was here occasioned. The female was married, and so predisposed to the exciting cause; regular in the menses, except when pregnant or suckling; and the interval between the birth of her last child and the suppression of the menses after weaning, corresponded to her former enceptions in equi-distance.

As to the symptoms-this case presents strikingly interesting differences from most on record. Sir C. M. Clarke considers "the occasional and sudden discharge of an almost colourless and inodorous watery fluid a most constant, indeed, a diagnostic symptom." Such discharges were entirely absent in this case, which was remarkable for the hæmorrhage, as it were, of a prolonged abortion. I can find only two cases on record of this repeated and prolonged hæmorrhage--one by Mr. Watson, in the Philosophical Transactions, the other illustrated in Cruveilhier's "Pathology of Anatomy," of which, however, I believe no clear exposition has yet been given by authors.

In my opinion, the presence of these hæmorrhages is evidently determined by the place of adherence of the spongy or hydatid mass near the os uteri, acting, in fact, as that of a placenta prævia; whereas, in cases of watery discharges, the attachment is more remote from the os uteri, and vesicles not immediately attached are occasionally burst, thus giving rise to them so frequently; the case of the hæmorrhagic discharges being evidently thus seen to be most rare, as the determining site of adhesion is most abnormal and uncommon.

With respect to diagnosis, I think, with Madame Boivin, that ballottement is the best, and should always be essayed for pregnancy in suspicious cases; and I would regard any case of protracted hæmorrhage, with uterine pains, as sadly overlooked, were no vaginal examination instituted. Should the case be suficiciently advanced, the stethoscope may be appealed to.

After death, when concealment or inadvertent removal of the mass has occurred, I would look for the limited placental mark, (as hydatids have a wider adhesion, and a corpus luteum, as confirmatory, the latter of pregnancy, the former of delivery. Should, however, a hydatid mass be presented to me, the presence of a fotus, or part of the ovum, would of course decide the point of impregnation at once; but not inversely, I believe; yet, with Dr. Montgomery, if acting as a medical jurist, should $I$ find no trace of either, $I$ would give the patient the benefit of the doubt-(if she required the charity) shadowy indeed - their absence perhaps not being real, but inferred, (as I would explain further than he has done,) from the occasional impossibility of finding them.

In addition to the suggestion of Dr. Davis, that hydatids may be the result of conceptions of antecedent dates, I would name two other causes of failure, in proving cotemporaneous gestation, hitherto, I believe, unnoticed-viz., 1st, a perfect or advanced degeneration, (that which was most probably a placenta in my case appearing so;) or, 2ndly, as hydatids are discharged frequently at intervals, and in separate masses, the very part which may happen to contain traces of the ovum or fœtus may be removed by design or indifference, (the second lot was thus carelessly thrown away in my case,) and so the examiner may fail to find what really existed.

To these views of hydatid etiology, it has been triumphantly objected, that the disease has coèxisted with a hymen. My reply to Mr. Andrews is perhaps uncharitable - viz., hymens are sometimes lucky; pregnancy has also coëxisted with the same. Vide Ramsbotham's cases and others.

Do these etiological views derive confirmation from coincidence with the patient's feelings? : Dr. Montgomery argues thus: "In every instance under our inspection, \&c., the women supposed themselves with child." My patient quite doubted her being so situated: I speak of her feelings, for this doubt arose from the presence of the ordinary tronblesome sympathetic effects now present, and really confirmatory, but to which she was unused on former occasions.

As to the time at which a ceded pregnancy is degenerating -is this indicated by any peculiar symptoms? Professor Burns says yes: "the mammse become flaccid, and the sympathetic effects of pregnancy cease." In my case, the breasts, though never much distended, did not become flaccid, and the vomiting and other sympathies were most urgent during the degeneration. The black stillicidium was here the first index.

The first discharge of blood commenced, in the majority of Madame Boivin's cases, at three months. She does not state how long they lasted. My case coincided with this period, but was remarkable in having hæmorrhage protracted to the sixth month.

Finally, with respect to the treatment, I place most confidence in the tincture of ergot, with sulphuric acid, and compound spirit of sulphuric ether. By these means I had no need of introducing the hand to detach or remove hydatids, or excite uterine contraction; manipulations " which must be done cautiously, and only when hremorrhage, or some other urgent symptom, occurs."-BuRns.

My case had been sufficiently hæmorrhagic, but I believe that the plug, till the os uteri is sufficiently dilated, conjointly with the ergot, will effectually control all hæmorrhage, whether intermediate or subsequent to the final expulsion of the hydatid masses; which latter is generally most alarming, from the extent of uterine surface from which they have been detached.

Grosvenor-street, Cheltenham, Feb. 1847.

\section{ON THE TREATMENT OF STRICTURE OF THE URETHRA BY HYDRAULIC DILATATION.}

\section{BY JOHN GOODMAN, EsQ., M.R.C.S.E., Broughton,} Manchester.

An individual from the country applied to me, a few days ago, with complete retention of urine, owing to a stricture just in front of the bulb of the urethra, from which he had suffered for a considerable perion. A bout two months before, an instrument had been passed, by a surgeon in the country, with considerable difficulty, which he stated to be about the size of a small catgut bougie, and he had since that time totally neglected all remedial measures, and had usually mic- 
turated in a twisted stream, about the size of a small crowquill. On the day of application for relief, he had been taking some beer, to which he attributed the closure of the passage, and had been unable to pass a drop of urine from an early hour in the morning. The bladder being now uncomfortably full, and a constant desire to micturate, attended with a good deal of pain, I attempted to pass the most appropriate bougies and catheters of various diameters, but failed in every attempt, and could not enable the patient to evacuate the smallest quantity of urine. What was to be done? The individual was very urgent-was on his way to Dublin-in much pain, and exceedingly desirous to be relieved before his departure. In this emergency, (one by no means uncommon,) the forcible application of a warm-water injection suggested itself. There was the soothing and spasm-subduing quality of the warm fluid,- the probable insinuating and permeative quality of a steadily increasing column, adapted for every condition, form, size, and situation of stricture; and there was also the gradually and slowly dilative power of hydraulic pressure, which, if sufficient force could be employed to enable it to perforate the contracted portion of the urethra without rupturing any of its walls, might be brought to bear with any amount of force which can be required.

With regard to the capability of perforation in an already formed channel, however reduced in size, the difficulty seemed to vanish when $I$ remembered having heard it stated that aqueous fluid can be forced through even the pores of iron itself when under immense pressure. It was borne in mind also, that this method of removing obstructions, (although of a very different kind, ) and of effecting a passage, is employed in all the other outlets of the human body-for instance, the ductus lachrymalis, meatus auditorius externus, Eustachian tube, \&c., (although the fluid employed in the last named is not exactly the same, yet the force is obtained by the same instrument.)

After introducing a gum catheter as far as the stricture, which was well secured by a band of tape, and a compress upon the penis to prevent escape, a syringeful of warm water was injected with some force, and was found to flow with tolerable ease. The patient exclaimed, "It passes." On removing the apparatus, the patient micturated immediately in a stream about the size of a crow-quill.

After some persuasion, rendered necessary partly by the satisfaction ensuing from being able to micturate, and partly from the slight pain endured during the injection, the apparatus was again connected as before. After this injection, which flowed still more readily, and the removal of the instrument and bandage, the stream was found to be considerably augmented. A pint of urine was passed in a very short space, and the patient went away completely relieved and well satisfied.

A question might arise, that if watery fluid is so capable of perforating and dilating the stricture, why does not the urine itself, with all the efforts made use of by the patient for emptying the bladder, produce the effect desired as readily as it can be accomplished by external means of the same nature?

To answer this question, the muscular power of the bladder was tested in the following manner:-A tube, filled with water, to which was previously joined a smaller one of glass, containing mercury, and so arranged as to exhibit the rise of the mercury in ratio with the existing pressure, was placed in communication with the urethra of a healthy individual, and secured by bandage and compress as before. He was then desired to make his most strenuous efforts to pass water. On so doing, the mercury in the small tube was found to rise only to the height of four or five inches, showing that the contractile force of the muscular coat of the bladder, aided by the abdominal muscles, is only equal to a column of water of four or five feet.

This small column, when compared with the effects capable of being produced by hand,--in the common lifting pump, the fire engine, and more especially by the hydraulic press,readily evince a good reason why an attempt might be made to force a passage through an obstruction which the muscular power of the bladder was incapable of effecting.

With such propitious results on the first trial of this method, I anticipate the relief of patients at all times under like circumstances; and even, perhaps, in those extreme cases where perforation of the bladder might otherwise be suggested, as well as in cases of spasmodic stricture.

And it may not be improbable that the cure of stricture itself may be somewhat facilitated by the employment of this remedial agent, unless it be found that the power of dilatation by the syringe is reduced considerably when free communication is established with the feeble walls of the bladder.

It is not improbable, that in practice the injection from the extremity of the catheter may be found to serve the twofold purnose also of directing and introducing, as well as dilating. the orifice of the stricture, for the passage of the catheter itself, during the flow of the injection.

Broughton, March, 1847.

\section{ON THE NON-DUALITY OF MIND}

$$
\text { IN ITS }
$$

\section{PHYSIOLOGICAL, PHRENOLOGICAL, AND.} PHILOSOPHICAL RELATIONS.

Bx THOMAS CATTELL, M.D., Braunston.

(Continued from p. 407, vol. i. 1846.)

THE PHYSTOLOGICAL AND PHRENOLOGICAI RELATTONS. OA DR. WIGAN'S DEFINITION OF MIND.

Tre definition to which I allude will be found in THe Lancer. of November the $22 \mathrm{nd}, 1845$.

This definition, with the connecting arguments, supports the hypothesis that the mind is " the aggregate of the mental functions and powers, whether exercised by one brain or two;" or that it is constituted by a complete series of mental operations, emotional instincts, propensities, and reasoning powers. Profound absurdity! How can a complete series of mental operations-which must, of necessity, include the reasoning powers-be associated, in character and kind, with the feelings and propensities? Or, in what manner can a complete series of mental operations, emotional instincts, and propensities, be the mind itself?

There must be a substance from which the mental operations proceed, and in which they unite, distinct from these operations; or, in the words of Paley's Natural Theology, "a centre in which perceptions mite, and from which rolitious flow." It is, besides, highly unphilosophical to conglomerate instincts, feelings, and propensities, qualities purely animal, with those only manifested by mind. The mind, an aggregate of the mental functions and powers! How so? Surely the hypothesis might have been, that the mind is the aggregate of its own functions and powers. But what can be proved in such a case, when a definition may be exacted of a function or a power?

We admit, in scientific pursuits, a distinction is made between function and organization; but slight reflection will convince any person that it is for the purposes of science only this distinction is resorted to. The structure of the brain is its anatomy, what that structure does is its physiology; the one has to do with the organ simply, the other with the function exclusively.

The term function, as must be evident, cannot be applicable to that which does not possess a structure, aliter, an organ. The mind is an indivisible entity, without structure and without parts; to speak, therefore, of the physiology of the mind analogously to that of the organs of the body, is to confound the radical distinctions which hold in the mental as in the physical world.

Aggregation of the mental functions presupposes the abstract existence of each function. But this notion cannot be corroborated, whether we regard the mind as a material or immaterial entity. In the one case there must be an organization originating their existence; and in the other, a substance in which such qualities unite, and from which they proceed.

The remark, then, that the great source of error in psychological pursuits is attributable to the wrong employment of terms and distinctions used merely as such for the convenience of science, will appear particularly apposite. This is very evident in the writings of those that are corrupted by the false and specious doctrines of materialism and phrenology. Who can dissociate function from organization without confusing our ideas? Are not function and organization essential to, and inseparable from, each other?

If a union of mental functions and powers possess an $a b-$ stract positive existence, (which the definition of Dr. Wigan unquestionably implies, ) and if such definition be insisted on, as constituting the mind, I would ask, if one of these functions were removed from this supposed agrgregation of divisible functions, will the mind retain its capabilities or not? If it retain them, then this subtracted function must have been superffuous and unnecessary, which will at once destroy the necessity of such an aggregation of functions. As the mind cannot retain its capabilities after a function or power is subtracted, I would further ask, is the function or power thus 